\title{
ERRATUM
}

\section{Genetics of Melanoma}

\section{Carlos A. Torres-Cabala and Jonathan L. Curry}

(C) Springer Science+Business Media New York 2016

C.A. Torres-Cabala, J.L. Curry (eds.), Genetics of Melanoma, Cancer Genetics, DOI 10.1007/978-1-4939-3554-3

\section{DOI 10.1007/978-1-4939-3554-3_13}

The affiliations of the book editors have been corrected. Please find below the updated affiliation details:

Carlos A. Torres-Cabala, MD, Associate Professor of Pathology and Dermatology, Chief of Dermatopathology Section, The University of Texas MD Anderson Cancer Center, Houston, TX, USA

Jonathan L. Curry, MD, Associate Professor of Pathology and Dermatology, The University of Texas MD Anderson Cancer Center, Houston, TX, USA 